\title{
Influence of vibration on the grain flow sensor during the harvest and the difference elimination method
}

\author{
Pengfei Qian ${ }^{1,2}$, Ting Lu $^{2,3}$, Cheng Shen ${ }^{3 *}$, Shuren Chen $^{1^{*}}$ \\ (1. Key Laboratory of Modern Agricultural Equipment and Technology, Ministry of Education, Jiangsu University, \\ Zhenjiang 212013, Jiangsu, China; \\ 2. School of Mechanical Engineering, Jiangsu University, Zhenjiang 212013, Jiangsu, China; \\ 3. Nanjing Institute of Agricultural Mechanization, Ministry of Agriculture and Rural Affairs, Nanjing 210014, China)
}

\begin{abstract}
The grain yield data collected by the intelligent yield measurement system of the combine harvester is generated into a field plot yield distribution map, which is of great significance for guiding agricultural production. However, in the process of drawing the yield map, the combine harvester is affected by vibration during operation and the generated error data in the process of collecting data which will cause the drawing results to be inaccurate. This study researched two factors that cause errors, then, the influence of vibration interference on the measurement signal was eliminated by filtering, vibration isolation, and designing a double-plates differential grain flow sensor. Three methods were taken to eliminate random errors, gross errors and systematic errors, including using the arithmetic average value to replace the true value, the $3 \sigma$ criterion, and removing the filling time data and the delaying time data. Finally, the grain yield distribution map was obtained through Matlab and Excel. The results showed that the interference frequency above $50 \mathrm{~Hz}$ could be eliminated by filtering, but it was difficult to filter the low-frequency signal which was close to the grain impact frequency. The vibration amplitude was reduced to $14.29 \%$ by adding a vibration isolation plate, and the SNR was increased from $-4.67 \mathrm{~dB}$ to $29.21 \mathrm{~dB}$ by combining low-pass filtering and damping vibration isolation. When the grain feeding rate was $2 \mathrm{~kg} / \mathrm{s}$, the natural vibration amplitude of the sensor after difference was about $0.02 \mathrm{~V}$ and evenly distributed around the zero voltage $0.2 \mathrm{~V}$. The influence of positive and negative offset on the average value of grain impact signal could be ignored, and the signal-to-noise ratio was increased from $29.21 \mathrm{~dB}$ to $62.49 \mathrm{~dB}$. The results of field experiments showed that the yield map drawn can clearly display the yield value of the harvest area, which is used to guide agricultural production.
\end{abstract}

Keywords: combine harvester, grain flow sensor, vibration interference, double-plates differential, elimination method DOI: $10.25165 /$ j.ijabe. 20211405.6748

Citation: Qian P F, Lu T, Shen C, Chen S R. Influence of vibration on the grain flow sensor during the harvest and the difference elimination method. Int J Agric \& Biol Eng, 2021; 14(5): 149-162.

\section{Introduction}

"Precision Agriculture" is a modern agricultural management concept based on information technology that has been recognized by people all over the world. It will face many challenges in the future $^{[1,2]}$, and also get good development opportunities ${ }^{[3-5]}$. More and more advanced technologies are applied in agriculture, such as the evaluation of soil, plants and environment through nanotechnology, which will promote the sustainable development of agriculture ${ }^{[6]}$. Real-time kinematics is applied to UAV positioning in precision agriculture ${ }^{[7]}$, which reduces the geolocation error. For example, Munnaf et al. ${ }^{[8]}$ used high-resolution soil and crop data fusion maps to sow seeds at specific locations for edible potato production. The grain yield

\section{Received date: 2021-05-08 Accepted date: 2021-08-13}

Biographies: Pengfei Qian, $\mathrm{PhD}$, Associate Professor, research interest: agricultural mechanization engineering, Email: pengfeiqian@ujs.edu.cn; Ting Lu, MS candidate, research interest: mechanical engineering, Email: 1622900813@qq.com.

*Corresponding author: Cheng Shen, PhD candidate, Assistant Professor, research interest: agricultural mechanization engineering. Nanjing Institute of Agricultural Mechanization, Ministry of Agriculture and Rural Affairs, No.100 Liuying, Xuanwu District, Nanjing 210014, China. Tel: +86-25-84346078, Email: shencheng@caas.cn; Shuren Chen, PhD, Professor, research interest: agricultural mechanization engineering. School of Agricultural Equipment Engineering, Jiangsu University, Zhenjiang 212013, Jiangsu, China. Tel: +86-13815486192, Email: srchen@ujs.edu.cn. information and location information collected by the combine harvester ${ }^{[9,10]}$ can also be used to draw grain yield maps to show the basic conditions of the farmland and guide field variable operations to achieve the ultimate goal of reducing agricultural production costs, reducing environmental pollution and achieving sustainable agricultural development.

There are many methods to measure grain yield, such as using the deep convolutional neural network of remote sensing images of drones for rice grain yield during rice maturity, and yield estimation by integrating spatial-spectral information ${ }^{[11]}$. Some scholars use RGB images to assess the grain yield of durum wheat at a low cost ${ }^{[12]}$. Other scholars use machine learning technology and multi-spectral RPAS images to estimate soybean yield ${ }^{[13]}$. In addition, grain impurities are also measured, such as by installing a rice grain impurity sensor in the combine harvester's granary ${ }^{[14]}$. The above grain yield measurement methods have specific measurement objects, but the varieties of grains are diverse, and grains of different growth periods may be encountered during work, so it is not appropriate to install a specific grain flow sensor on the combine harvester. Combining the characteristics of these grains, it is necessary to select a flow sensor that can be used on multiple occasions to improve the accuracy of grain yield.

The harvester will be disturbed by vibration when it is working, which has a great influence on the measurement of the sensor. In order to solve the problem of measuring the same frequency signal of flow signal and vibration interference at the same or similar 
frequency, Jiang et al. ${ }^{[15]}$ proposed a signal processing method that combines frequency change with amplitude characteristics. Errors in the measurement due to vibration, Duan et al. ${ }^{[16]}$ proposed a dual-channel interferometer (DCI) for anti-vibration optical measurement. In order to eliminate the aerodynamic lift vibration problem of rigid rotor helicopters, Lyu et al. ${ }^{[17]}$ proposed a new method for sinusoidal trimming of AC voltage in electrical engineering, but the above method is not suitable for reducing sensor vibration. Error data also has an impact on the accuracy of the yield map, therefor Lee et al. ${ }^{[18]}$ proposed an online update method for big data analysis, after accurately observing the measurement results, the measurement error deviation can be corrected. Meyer et al. ${ }^{[19]}$ can improve measurement accuracy by decomposing TES to understand the source of measurement error. Lu et al. ${ }^{[20]}$ studied the impact of the pixel extraction error of the measurement point on the overall measurement error, and established an error propagation model to reduce the overall measurement error. The above research provides a solution for improving the measurement accuracy, but it is not the same as the actual situation of reducing the vibration of the sensor. Therefore, it is necessary to study the effect of reducing the vibration on the plate from the perspective of the vibration of the plate.

In this study, the impact grain flow sensor was selected and the grain yield was obtained through the impulse theorem. Through finite element analysis, the location of the strain gauge was determined. Filtering, vibration isolation, and double-plates differential methods were used to eliminate the interference caused by vibration. For the error data, the arithmetic average was used instead of the true value to eliminate random errors. The error data was filtered with the $3 \sigma$ criterion to eliminate gross errors, and then system errors were eliminated by setting the filling time and delay time. Finally, the yield information obtained was drawn through MATLAB to draw contour maps and scatter plots of grain yield to obtain the field yield distribution, and by drawing the yield histogram through Excel, the number of output in each yield interval was obtained, so as to make future planting plans to guide field agricultural production.

\section{Materials and methods}

\subsection{Principle and structure of impact grain flow sensor}

The impact type grain flow sensor has a simple structure and significant advantages in both performance and economy. After calibration and data processing, it can achieve high measurement accuracy and is widely used in grain yield monitoring systems. When the combine harvester is harvesting, the grain is transported to the top of the granary through the net grain elevator, and the grain with a certain speed is thrown to the flow sensor strike plate. When grain periodically hits the plate, the resistance value of the resistance strain gauge attached to the back of the plate will change as the plate is deformed. According to the definition of impulse in physics $^{[21]}$, when the speed of grain impact is known, real-time measurement of grain mass can be achieved by measuring the change in momentum before and after the grain impact. The concrete working principle is shown in Figure 1.

The impact grain flow sensor ${ }^{[22]}$ includes five parts: impact plate, elastomer, bracket, strain bridge and signal conditioning circuit. Its structure is shown in Figure 1. The impact plate is installed at the end of the elastomer of a double-hole parallel beam, the upper end of the elastomer is installed on the bracket, and the bracket is fixed on the grain outlet of the combine harvester. Four strain gauges are attached to the stress concentration of the elastomer to form a Wheatstone bridge. When the combine harvester is in operation, the Wheatstone strain bridge outputs an impact signal of $0-5 \mathrm{mV}$, and the impact signal is amplified to 0 $2.5 \mathrm{~V}$ by the signal conditioning circuit.

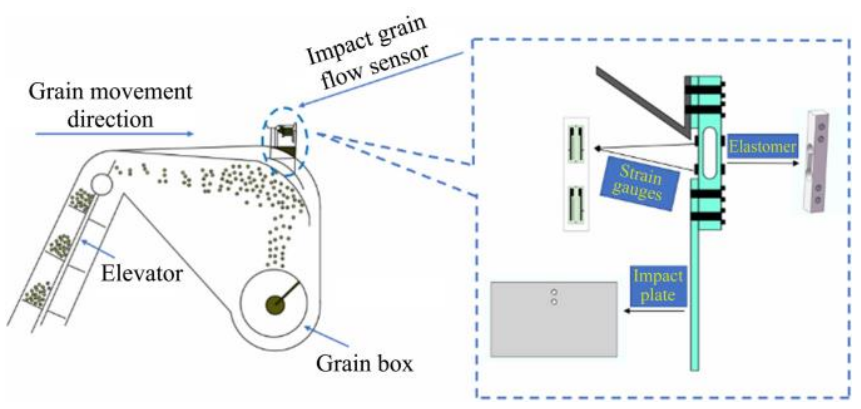

Figure 1 Working principle diagram of grain flow sensor

The function of the impact plate is to receive the impact of the grain and transfer the scattered impact force of the grain to the end of the elastomer. In order to detect the grain impact of the grain outlet of the combine harvester as completely as possible, the size of the impact plate should be equivalent to the size of the grain outlet. The material of the impact plate can be $4 \mathrm{~mm}$ thick polymethylmethacrylate plexiglass, PVC engineering plastics, etc. Two positioning holes with a diameter of $5 \mathrm{~mm}$ were opened in the center of the impact plate, which was fixed to the end of the elastomer by bolts. The elastomer was made of hard aluminum alloy with length $\times$ width $\times$ thickness of $80 \mathrm{~mm} \times 12 \mathrm{~mm} \times 12 \mathrm{~mm}$. Along the centerline of the elastomer, two parallel holes with a distance of $20 \mathrm{~mm}$ and a diameter of $10 \mathrm{~mm}$ were opened. The two holes were connected with a distance of $8 \mathrm{~mm}$ to form a double-hole parallel cantilever beam. The double-hole parallel beam had the characteristics of high structural rigidity, good stability, high sensitivity, anti-eccentric load and strong anti-lateral ability. Two positioning holes with a diameter of $5 \mathrm{~mm}$ were opened at the upper end of the elastomer for fixing with the bracket. Two screw holes with a diameter of $5 \mathrm{~mm}$ were opened at the lower end for fixing the impact plate. The bracket was the same size as the grain outlet frame of the combine harvester, with a thickness of $2 \mathrm{~mm}$, and was fixed on the body of the combine harvester through 6 positioning holes. The upper side and the left and right side plates of the bracket form a flow guiding mechanism. The bracket was opened directly in front and below, the front was used for hanging the impact plate, and the lower opening was used for rice drop.

The grain is ejected from the grain outlet at a high speed and impacts on the impact plate, and falls freely into the grain box under the action of gravity. The typical structure of a resistance strain gauge is composed of a sensitive grid, a substrate, a coating layer and a lead wire. Through the resistance strain effect of the sensitive grid, the strain of the elastomer is transformed into a resistance change. Four $320 \Omega$ wire grid resistance strain gauges are attached to the four weak points A, B, C, and D of the double-hole parallel beam. The wire grid resistance strain gauge is only sensitive to the strain in the length direction of the metal wire, and the sensitive direction of the strain gauge is along with the length direction of the elastic beam.

\subsection{Determination method of strain gauge position in sensor}

The single-plate impact grain flow sensor is a sensor based on the law of stress and strain. The stress distribution of the grain flow sensor under the action of external force is an important basis for attaching strain gauges. In order to preliminarily determine the suitable location for attaching the strain gauges, it is necessary 
to load uniform pressure and concentrated force on the loading plane at different positions to observe the stress distribution and find the stress concentration point from the stress distribution diagram. Firstly, the three-dimensional solid model of the impact plate of the grain flow sensor was established in Solidworks software, as shown in Figure 2, then the model was imported into Ansys for unit division and boundary condition setting as shown in Figure 3, and finally stress loading and analysis were performed.

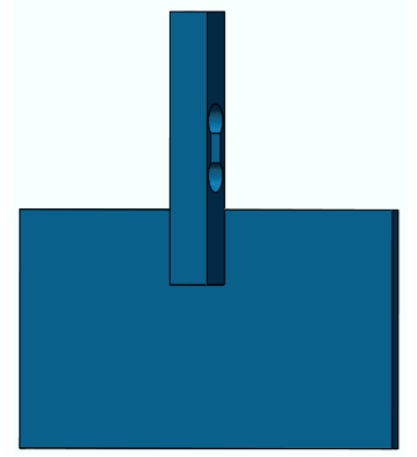

Figure $23 \mathrm{D}$ model of impact plate

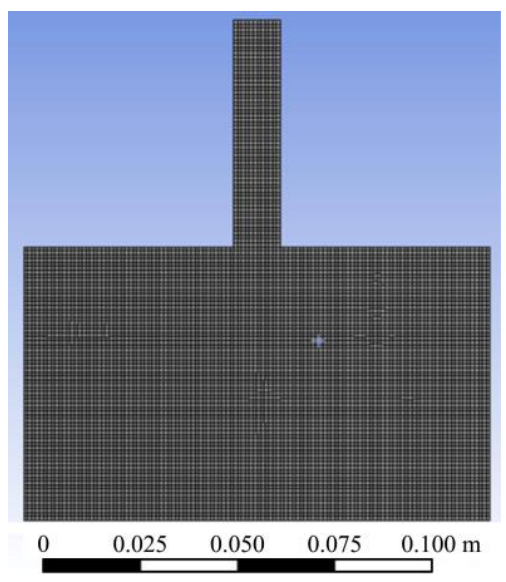

Figure 3 Impact plate meshing diagram

In mechanical analysis, the stress calculation methods include the stress of the first strength theory, the stress of the second strength theory, the stress of the third strength theory, the stress density and the effective stress. In this study, the effective stress of Von Mises is used to analyze the stress distribution of the sensor. Generally, the effective stress calculation method of Von Mises is as follows ${ }^{[23]}$ :

$$
\delta=\sqrt{\frac{1}{2}\left[\left(\delta_{x}-\delta_{y}\right)^{2}+\left(\delta_{y}-\delta_{z}\right)^{2}+\left(\delta_{x}-\delta_{z}\right)^{2}\right]}
$$

where, $\delta_{x}, \delta_{y}$, and $\delta_{z}$ represent the three principal stresses; $\delta$ represents the yield point of the material.

\subsection{Ways to eliminate vibration interference during harvest}

Through the analysis of the impact signal when the sensor was subjected to vibration, different solutions were determined to gradually eliminate the interference of vibration to the sensor during the operation. First, the grain impact signal was obtained when the sensors is not subjected to vibration, and got its impact frequency. Through the simulated field test, the impact signal was obtained and the impact frequency under the simulated working condition was obtained through the fast Fourier transform, and the high-frequency signal was removed by filtering. Then, by adding a vibration isolation plate and designing a double-plate differential impact grain flow sensor could eliminate further vibration interference, obtain the differential zero point voltage, determine that the impact signal of the plate's natural vibration output was positive and negative distributed near the zero point voltage and eliminated vibration interference.

2.3.1 Method of obtaining impact signal parameters without vibration interference

The main experimental equipment was a single-plate impact grain flow sensor, and the rice grain. The grain flow rate was divided into three groups of $0.2 \mathrm{~kg} / \mathrm{s}, 0.7 \mathrm{~kg} / \mathrm{s}$, and $2 \mathrm{~kg} / \mathrm{s}$, which were respectively hit on the impact plate. Under the action of impact force, the elastic body fixedly connected with the impact plate would produce elastic deformation, which would cause the resistance value of the strain gauge on the elastic element to change. The signal circuit amplified and adjusted the signal and output it, and then used the single-chip data acquisition circuit to collect the dynamic voltage signal during the grain impact process. The amplitude, frequency and power of the grain impact signal without vibration interference were obtained.

2.3.2 Influence of combine harvester vibration on impact grain flow sensor

The unbalanced movement of the combine harvester brings complex vibration interference when it is working, such as engine pistons, cutters, vibrating screens and other components reciprocating at high speeds at different frequencies. In order to suppress the vibration signal, it is necessary to measure the vibration signal of the combine harvester under different working conditions and analyze its spectral characteristics, so as to provide a basis for eliminating interference.

The main test equipment was a combine harvester ${ }^{[24]}$, a grain flow sensor, a signal acquisition circuit and a computer, and the sampling frequency was $1 \mathrm{kHz}$. The grain flow sensor adopted a self-made single-plate impact grain flow sensor, which was installed in the grain outlet of the clean grain elevator of the combine harvester, and used MATLAB to perform frequency spectrum analysis on the vibration signal. Combine harvester operations could be divided into six working conditions, as shown in Table 1. Among them, the vibration signal source of idle speed condition and high-speed standby was only the engine, and the vibration signal of threshing idling was the vibration superposition of the moving parts of the combine harvester. The idling of the header and the ground walking increased the uncertainty factors caused by the ground impact and grain load changes.

\begin{tabular}{cccc} 
Table 1 & Vibration signal source of crawler combine harvester \\
$\begin{array}{c}\text { Serial } \\
\text { number }\end{array}$ & $\begin{array}{c}\text { Working } \\
\text { condition }\end{array}$ & Feature & $\begin{array}{c}\text { Vibration } \\
\text { source }\end{array}$ \\
\hline 1 & $\begin{array}{c}\text { Idle speed } \\
\text { condition } \\
\text { High-speed } \\
\text { standby }\end{array}$ & $\begin{array}{c}\text { Idle speed after engine } \\
\text { start, low frequency } \\
\text { The engine is carried to the } \\
\text { Maximum speed idling }\end{array}$ & Engine \\
2 & $\begin{array}{c}\text { Threshing } \\
\text { idling }\end{array}$ & $\begin{array}{c}\text { Close the threshing clutch, } \\
\text { the speed is 0 }\end{array}$ & $\begin{array}{c}\text { Engine, header, threshing } \\
\text { mechanism, vibrating } \\
\text { screen, auger, etc. }\end{array}$ \\
3 & $\begin{array}{c}\text { Idling of } \\
\text { header } \\
4\end{array}$ & $\begin{array}{c}\text { Close the header clutch, the } \\
\text { vehicle speed is 0 }\end{array}$ & $\begin{array}{c}\text { Increased header } \\
\text { vibration }\end{array}$ \\
5 & $\begin{array}{c}\text { Ground } \\
\text { walking }\end{array}$ & All parts work without load & $\begin{array}{c}\text { Increased ground } \\
\text { impact }\end{array}$ \\
6 & Normal harvest & All parts are loaded & Increased grain impact
\end{tabular}

According to the basis of signal analysis ${ }^{[25]}$, for the time-domain continuous vibration signal $U(t)$, the average power of the grain impact signal is

$$
P_{s}=\frac{1}{T} \int_{0}^{T}[U(t)-1] \mathrm{d} t
$$

For the discrete digital signal $U(n)$ with a sampling frequency 
of $1 \mathrm{kHz}$, the calculation method of the average power of the vibration signal is

$$
P_{n}=\frac{1}{1000} \sum_{n=0}^{999}[U(n)-1]^{2}
$$

Knowing the power of the grain impact signal and the power of the vibration interference signal of the combine harvester, the signal-to-noise ratio can be calculated as follows:

$$
\mathrm{SNR}=20 \lg \frac{P_{s}}{P_{n}}
$$

where, SNR is signal-to-noise ratio; $P_{s}$ is the power of grain impact signal; $P_{n}$ is the power of vibration interference signal; $U(t)$ and $U(n)$ represent vibration signal and discrete digital signal respectively.

\subsubsection{Using filtering method to reduce vibration interference}

There are five types of filters: low-pass, high-pass, band-pass, band-stop, and comb filtering, which can effectively filter the frequency point of a specific frequency in the power signal or frequencies other than the frequency point to obtain a power signal of a specific frequency, or the power signal after eliminating a specific frequency. The vibration signal of the grain flow sensor collected by the acquisition circuit was subjected to fast Fourier transform to obtain the frequency of the impact signal. Compared with the frequency when there was no vibration interference, part of the interference signal could be removed. Therefore, a low-pass filter ${ }^{[26]}$ could be designed for the grain flow sensor to filter the interference signal.

2.3.4 Using vibration isolation method to reduce vibration interference

Since low-pass filters can only filter high-frequency vibration signals, vibration isolation materials were used to further reduce the amplitude and propagation of vibration signals ${ }^{[27]}$. Vibration isolation is divided into two types: active vibration isolation and passive vibration isolation. Active vibration isolation is to avoid the influence of vibration equipment in the surrounding environment, and passive vibration isolation is to protect the measuring instrument from the influence of basic vibration. In order to isolate the grain flow sensor from the vibration of the combine harvester, passive vibration isolation should be adopted. With reference to Kwon et al. ${ }^{[28]}$, a multi-layer blade isolator for a spaceborne cooler was proposed, which adopted a passive vibration isolation method to reduce the micro-jitter of a space cryogenic cooler. This study prepared two pieces of silicone rubber vibration isolation plate with a length $\times$ width $\times$ thickness of $12 \mathrm{~mm} \times$ $20 \mathrm{~mm} \times 3 \mathrm{~mm}$, and two installation holes with a diameter of $5 \mathrm{~mm}$ were reserved on the vibration isolation plate. One piece was installed between the bracket and the elastomer, and the other piece was installed between the impact plate and the elastomer, as shown in Figure 4.

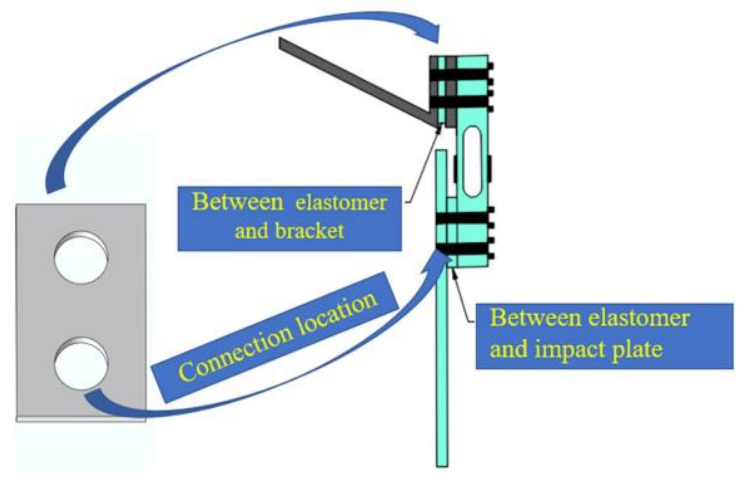

Figure 4 Vibration isolation sheet and installation location
2.3.5 Reducing vibration interference by designing double-plate differential

The single-plate impact grain flow sensor could not completely eliminate the vibration interference, so a double -plate differential impact grain flow sensor was designed for this purpose, and it was expected that the vibration interference could be eliminated by the differential method. The structure of the sensor was shown in Figure 5a. Two plexiglass plates of the same size were respectively fixed on the double-hole parallel cantilever elastomer as a detection plate. The four stress concentration points of each elastomer were attached with 4 strain gauges. It formed two identical Wheatstone bridges and converted strain signals into electrical signals. The positioning holes of the two cantilever beams were installed on the same hole position of the diversion bracket by two fixed screws, and the middle was separated by a gasket, so that the front and rear detection boards were parallel and did not contact each other. Three vibration isolation plates were used to reduce vibration signal interference. One of the vibration isolation plates was installed between the bracket and the elastic beam, and the remaining two vibration isolation plates were installed between the impact plate and the elastomer and the vibration detection plate and the elastomer, respectively. The real object is shown in Figure 5 b.

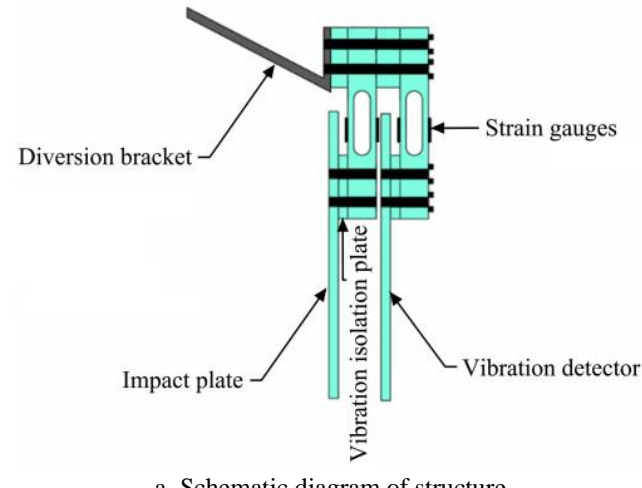

a. Schematic diagram of structure

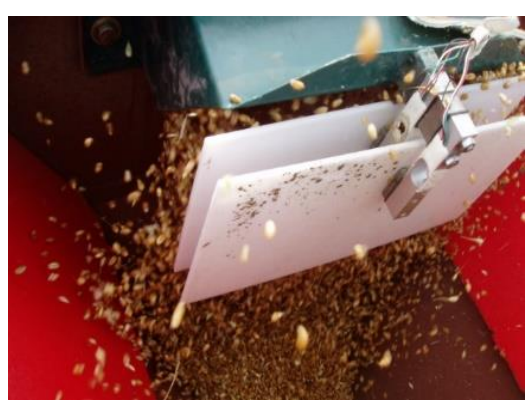

b. Physical diagram

Figure 5 Double-plate differential impact grain flow sensor

The two detection boards are the same size as the grain outlet of the combine harvester. The front detection plate bears the impact of the grain and is called the impact plate. The rear detection plate does not bear the impact of the grain, but can detect the vibration of the combine harvester itself. So it is named the vibration detection board. After the grain impacts on the front impact board, it falls and will not rush to the rear detection board. The size and material of the two detection boards are exactly the same, so they have exactly the same dynamic characteristics. The two detection boards are installed in the same hole position. The detected vibration is a pair of common-mode signals. Differential method can be used to eliminate vibration signals and improve the signal-to-noise ratio, the equation for calculating the power of the vibration signal before and after the difference is as follows ${ }^{[25]}$ : 
The vibration signal power of the two channels before the difference are

$$
\begin{aligned}
& P_{A}=\frac{1}{1000} \sum_{n=0}^{999}\left[U_{A}(n)-1\right]^{2} \\
& P_{B}=\frac{1}{1000} \sum_{n=0}^{999}\left[U_{B}(n)-0.8\right]^{2}
\end{aligned}
$$

The power of the vibration signal after the difference is

$$
P_{A B}=\sum_{n=0}^{999}\left[\Delta U_{A B}(n)-0.2\right]^{2}
$$

where, $P_{A}$ and $P_{B}$ represent the vibration signal power of the two channels before the difference; $P_{A B}$ represents the vibration signal power after the difference.

\subsection{Error data processing method}

In the process of drawing the grain yield map, the measurement error of the sensor was solved. It was still necessary to consider some error data obtained due to human factors in the measurement process, and these error data needed to be eliminated before drawing the yield map. Random errors can appear in many aspects, in terms of the correlation of digital images based on subsets, $\mathrm{Su}$ et al. ${ }^{[29]}$ obtained the relationship between the second-order shape function and the first-order shape function random error. Since the field grain harvest experiment was a non-repeatable experiment, the arithmetic average value was used as the true value of the measured yield to reduce the influence of random errors. The value of gross error generally deviated more from the normal value. In the original yield data, gross errors caused by various reasons were bound to exist. In order to eliminate these gross error data, the $3 \sigma$ criterion could be used to process the original yield data. The systematic error is that it causes the measurement result to deviate in one direction, and its value is constant or changes according to a certain law. The main forms of system error in this study were filling time error and delay time error. The influence of system error was eliminated by getting rid of filling time error data and delaying time error data.

\subsection{Method of drawing yield map}

Using the grain yield distribution map system, a field plot yield distribution map can be generated from the grain yield data collected by the combine harvester's intelligent yield measurement system. The yield distribution map can intuitively and clearly reflect the yield distribution information of the plot, and find the reasons for the yield difference, so as to formulate the corresponding fertilization and crop disease removal plan for the next year's planting ${ }^{[30-32]}$, also can play an extremely important guiding role in subsequent precision agriculture practices. However, since the current yield monitoring system is not perfect in all aspects and the accuracy of the yield data obtained is not very high, the data without error processing directly participates in the calculation work of the yield map generation, which will inevitably have a great impact on the accuracy of the production map ${ }^{[33-35]}$. Therefore, this study improved the instrument and eliminated the error data before drawing the grain yield map. From the perspective of the comprehensive yield maps on the market, the yield maps drawn in this study mainly included yield data scatter maps, yield data contour maps, and yield data histograms.

In order to adapt to different situations, it is often necessary to use different coordinate systems to represent GPS positioning data, which requires a projection transformation of the coordinate system. The common plane rectangular coordinate system uses coordinate projection transformation to map spatial coordinates (spatial rectangular coordinates or spatial geodetic coordinates) to the plane through mathematical transformation. For example, geodetic coordinates are transformed into the rectangular coordinates of length $(X)$, width $(Y)$ and height $(Z)^{[36]}$, and then the obtained yield information is made to correspond with the coordinate information, and finally the graphs are drawn.

2.5.1 Method of drawing scatter map of yield data

Scatter maps are widely used. For example, Rao et al. ${ }^{[37]}$ used scatter maps to perform rigorous analysis of loop flow signals. The grain yield scatter map is to draw a curved surface through discrete points, and observe the yield value of the corresponding area through the height of the points on the curved surface. The mapping software uses MATLAB 2018. The coordinates and the corresponding yield value are input, and the system will get the corresponding yield data scatter map as shown in Figure 6. The height of the $(X, Y)$ point on the yield map represents the yield value $\left(\mathrm{kg} / \mathrm{hm}^{2}\right)$ in the area.

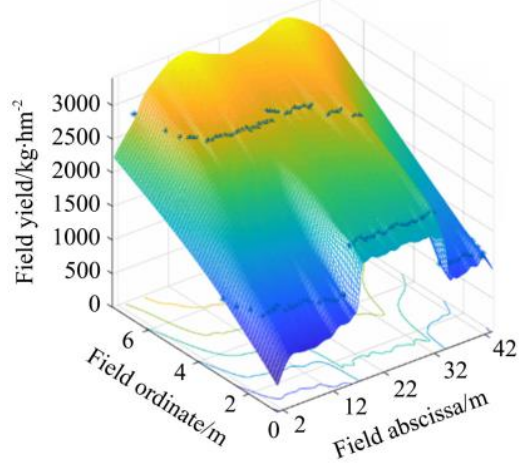

Figure 6 Scatter map of yield data

\subsubsection{Method of drawing contour map of yield data}

The contour method is one of the commonly used methods for the visualization of two-dimensional field data sets. For example, contour maps were used to represent the changes in $\mathrm{CO}$ emissions with engine load and biodiesel content ${ }^{[38]}$. Another example is that Lee et al ${ }^{[39]}$ realized the actual stack design with bending-twist coupling by superimposing the contour map on the stack parameter design space. In precision agriculture, the distribution of soil nutrient content, moisture content, distribution of diseases and insect pests, and grain yield distribution can also be represented by contour lines. This study used contour maps to observe the grain yield distribution in the field area. The contour map was also drawn by using MATLAB software. After the coordinates and the corresponding yield value were input, the system generated the contour map, as shown in Figure 7.

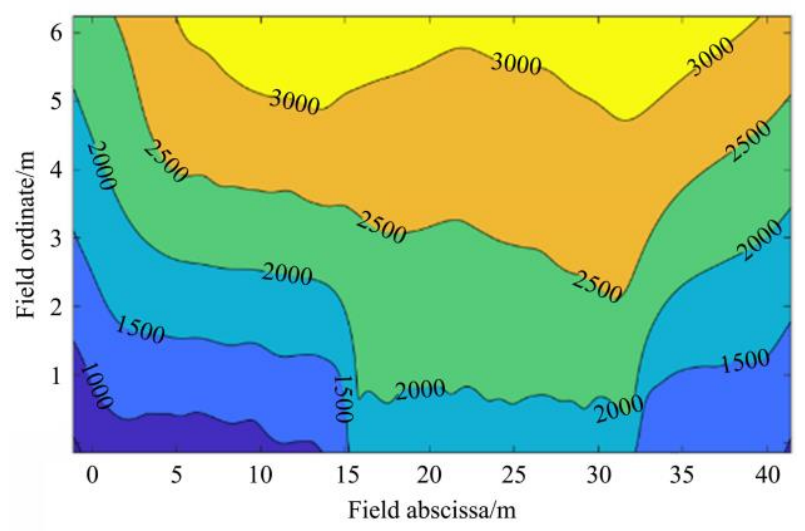

Note: Areas on each contour line indicate that their yield values are the same. Figure 7 Contour map of yield data

\subsubsection{Method of drawing histogram of yield data}

The histogram can show the relationship between several variables through data. Nousi et al. $^{[40]}$ proposed a dense 
convolution feature histogram for powerful visual object tracking. This study also used a histogram to show the relevant data of the yield. The yield data histogram was drawn by Excel, and the three-dimensional histogram was selected. Compared with the two-dimensional histogram, it could not only the number of yields in a certain yield interval in all the collected yield data, but also see the proportion of the number of yields in this region to the total yield. The drawing method is to organize the collected yield data, divide the yield interval, obtain the yield number of the yield interval, then obtain the proportion of the yield interval, and select two columns of data to draw the histogram, finally the result is shown in Figure 8.

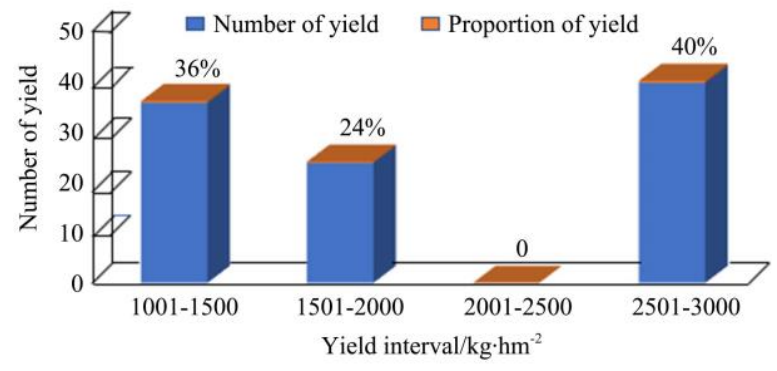

Figure 8 Histogram of yield data

\section{Results and discussion}

\subsection{The location of the sensor strain gauge}

First, a uniform pressure of $100 \mathrm{~N}$ was applied on the impact plate to solve the stress distribution cloud diagram of the elastomer under the uniform force. Then, a concentrated force of $100 \mathrm{~N}$ was applied to different nodes on the central axis of the sensor to calculate the stress distribution of the elastomer under the action of the concentrated force. Figure 9a shows the effective stress distribution cloud diagram of von Mises after the simulated application of $100 \mathrm{~N}$ uniform pressure on the impact plate of the grain flow sensor. Stress concentration occurs at the four weak points A, B, C, and D of the elastomer, as shown in Figure 9b.

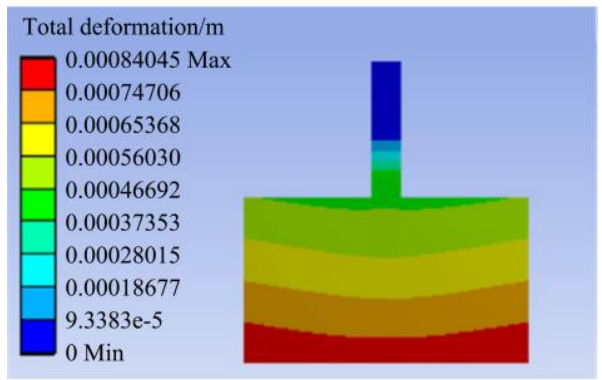

a. Front view

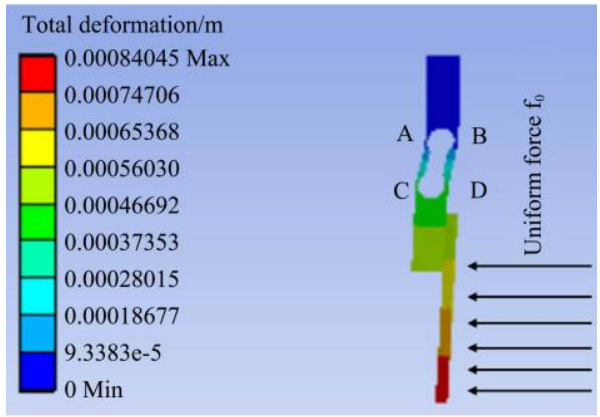

Note: Stress concentration occurs at the four weak points A, B, C, and D, the same as below.

$$
\text { b. Left view }
$$

Figure 9 Stress distribution cloud diagram under the action of uniform force
A concentrated force of $100 \mathrm{~N}$ was applied to the four different positions of the force arm on the sensor impact plate. The effective stress distribution cloud diagram is shown in Figure 10. It can be found from the figure that the concentrated stress acts on four different points of action, and the stress concentration points of the elastomer are all at the same position.

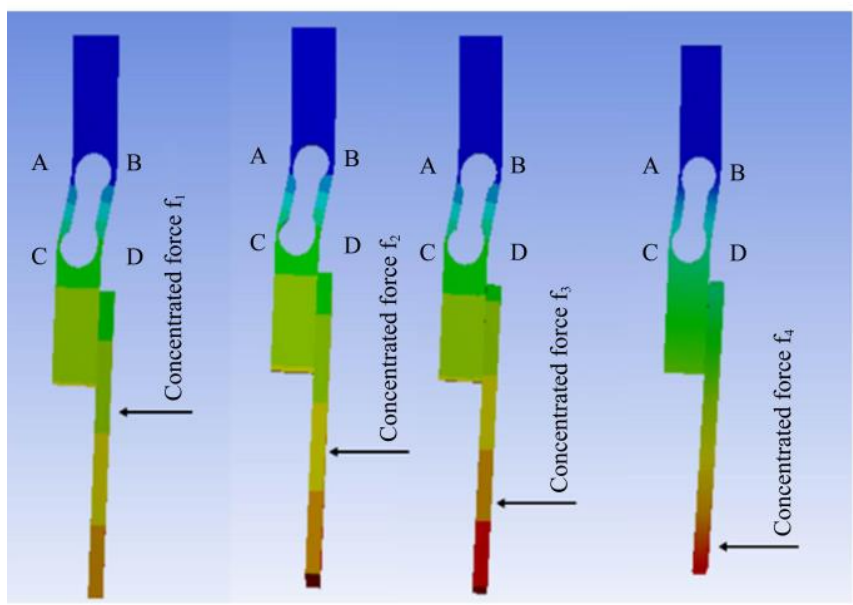

Figure 10 Stress distribution cloud diagram under concentrated force

To sum up, because the elastomer of the double-hole parallel beam structure had stress concentration at four points A, B, C, and $\mathrm{D}$, the strain that occurred at the stress concentration point was also the largest. Therefore, the strain gauges of the grain flow sensor should be attached to these positions.

\subsection{Analysis of impact signals when there is no vibration interference}

When the grain flow rate was about $0.2 \mathrm{~kg} / \mathrm{s}$, the collision process is shown in Figure 11. Based on reference ${ }^{[41]}$, there was one collision within $1 \mathrm{~s}$, and the time of each collision was about $33 \mathrm{~ms}$. There was an impact signal corresponding to the collision process. The impact signal waveform was similar to an isosceles triangle. The height of the triangle was about $0.6 \mathrm{~V}$, the base of the triangle was $30 \mathrm{~ms}$, the average impact voltage per second was about $0.009 \mathrm{~V}$, and the average power of the grain impact signal was $4.5 \mathrm{~mW}$.

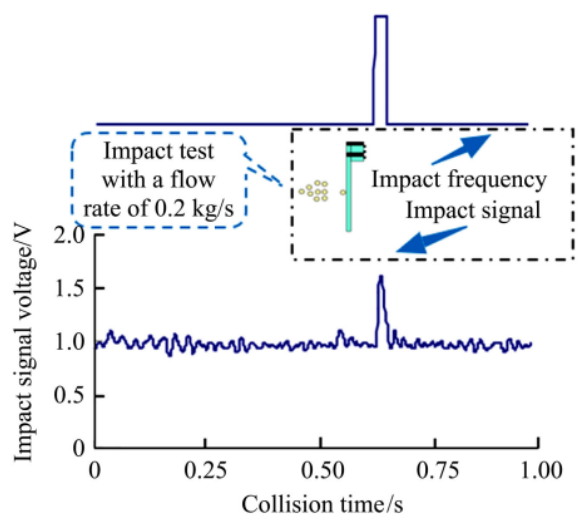

Figure 11 Collision process 1 and impact signal (Flow rate $=0.2 \mathrm{~kg} / \mathrm{s}$ )

When the grain flow rate was about $0.7 \mathrm{~kg} / \mathrm{s}$, the collision process is shown in Figure 12. There were three collisions within $1 \mathrm{~s}$, and the time of each collision was about $33 \mathrm{~ms}$. There were three impact signals corresponding to the collision process. The impact signal waveform was similar to an isosceles triangle. The height of the triangle was about $0.65 \mathrm{~V}$, and the base of the triangle was $30 \mathrm{~ms}$. The average power of the grain impact signal was 
approximately $14.5 \mathrm{~mW}$

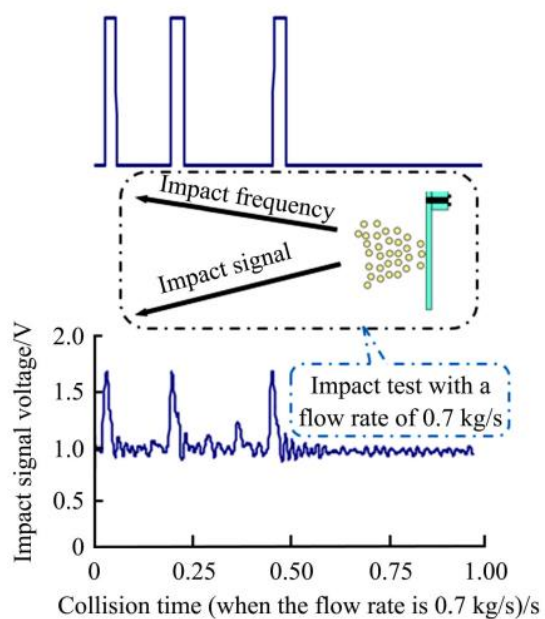

Figure 12 Collision process 2 and impact signal (Flow rate $=0.7 \mathrm{~kg} / \mathrm{s}$ )

When the grain flow rate was $2 \mathrm{~kg} / \mathrm{s}$, the collision process is shown in Figure 13. There were 13 collisions within $1 \mathrm{~s}$, and the time of each collision was about $30 \mathrm{~ms}$. There were 12 impact signals corresponding to the collision process. The impact signal waveform was similar to an isosceles triangle. The height of the triangle was about $0.6-0.7 \mathrm{~V}$. The peak value of individual impact signals reaches $1 \mathrm{~V}$. The base of the triangle was $30 \mathrm{~ms}$. The average power of the grain impact signal was about $54 \mathrm{~mW}$.

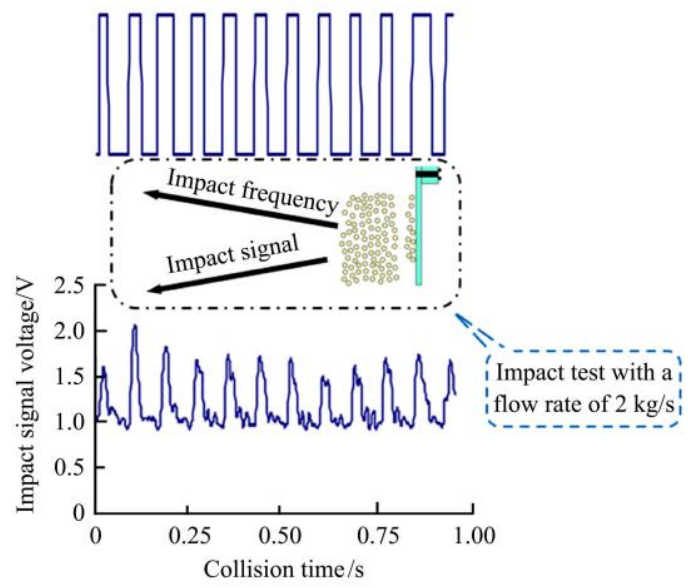

Figure 13 Collision process 3 and impact signal (Flow rate $=2 \mathrm{~kg} / \mathrm{s}$ )

The collected grain impact signal waveform showed that the peak value of a single grain impact signal was about $0.6-0.7 \mathrm{~V}$, and the power of a single impact signal was about $4.5 \mathrm{~mW}$. When the grain flow rate was $2 \mathrm{~kg} / \mathrm{s}$, the peak value of the impact signal was also about $0.6 \mathrm{~V}$, the frequency of the grain impact signal was about $13 \mathrm{~Hz}$ to $14 \mathrm{~Hz}$, and the average power of the impact signal was about $54 \mathrm{~mW}$.

\subsection{Analysis of the influence of combine harvester vibration on impact signal}

In order to analyze the vibration characteristics of the moving parts of the combine harvester, the combine harvester was operated under the first four working conditions in Table 1, and each working condition worked stably for $5 \mathrm{~min}$. The single-chip microcomputer data acquisition circuit was used to collect the output signal of the grain flow sensor. In order to observe the mixing of the grain impact signal and the vibration signal, the grain was fed into the combine harvester to simulate normal harvesting conditions. The vibration signals of the four working conditions within $1 \mathrm{~s}$ are shown in Figure 14. The vibration signal amplitude of idle speed and high-speed standby conditions was about $0.1 \mathrm{~V}$, and the vibration signal amplitude of threshing idling and header idling was about $1 \mathrm{~V}$. According to the impact test, it was concluded that the peak value of the grain impact signal was about $0.6 \mathrm{~V}$. Compared with the grain impact signal amplitude, the vibration signal amplitude of idle speed and high-speed standby was smaller than that of grain impact signal, and the vibration signal amplitude of threshing idling and header idling was larger than that of grain impact signal.
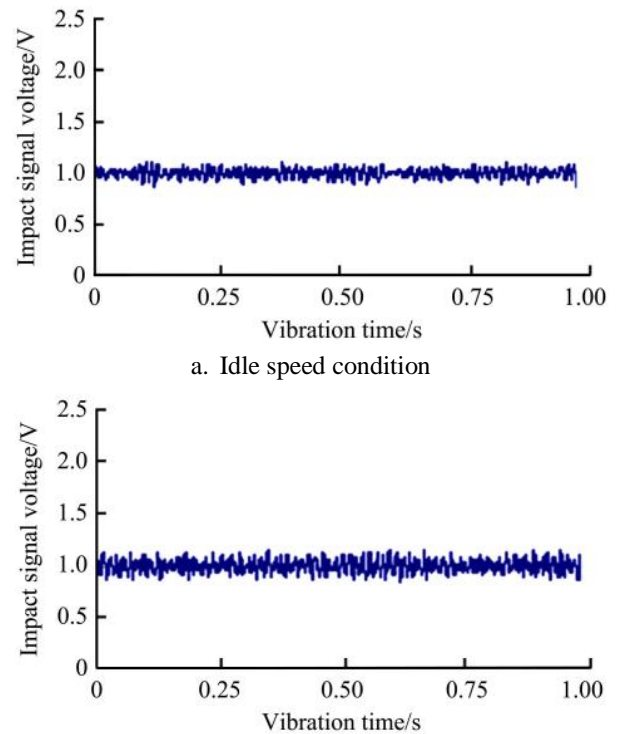

b. High-speed standby condition

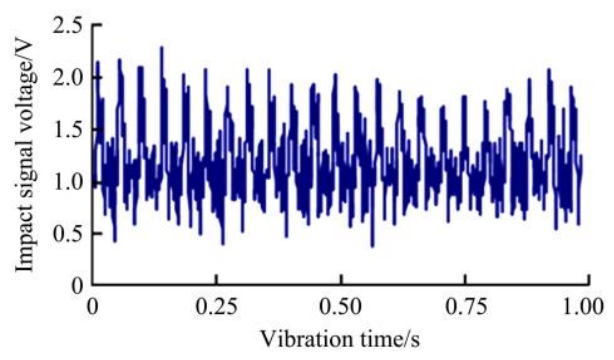

c. Threshing idling condition

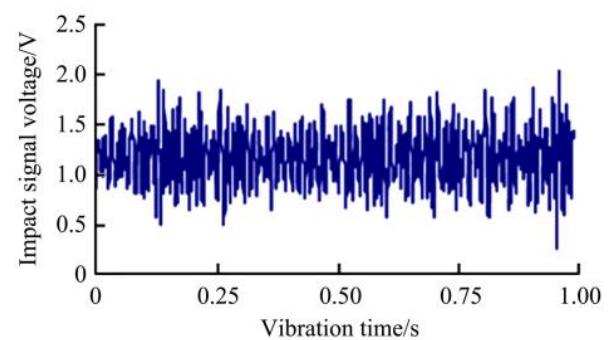

d. Header idling condition

Figure 14 Vibration interference of grain flow sensor under different working conditions

From the vibration signal of the combine harvester, it could be found that the vibration interference amplitude of the combine harvester was relatively small when the engine was idle and high. When the threshing drum and the header were working at the same time, the vibration amplitude of the combine harvester exceeded the amplitude of the grain impact signal. When the combine harvester was under normal harvesting conditions, grain was fed to the combine harvester, and the superposition of the impact signal and the vibration signal could be obtained. Figure 15a showed the impact signal when the feed rate was $0.2 \mathrm{~kg} / \mathrm{s}$. There was a grain impact within $1 \mathrm{~s}$, but it was difficult to distinguish the impact 
signal from the vibration signal. Figure $15 \mathrm{~b}$ shows the impact signal when the feed rate was about $1.1 \mathrm{~kg} / \mathrm{s}$, and the impact signal was almost submerged in the vibration signal. Peng et al. ${ }^{[42]}$ proposed a processing method of using digital signals to eliminate signal interference in eliminating signal channel interference, but it was limited to the same channel and was not suitable for vibration signals doped in grain impact signals. Therefore, it was necessary to design a new solution to the vibration interference.

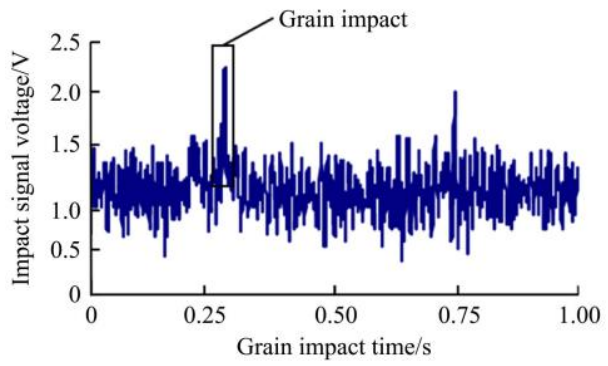

a. Feeding amount is $0.2 \mathrm{~kg} / \mathrm{s}$

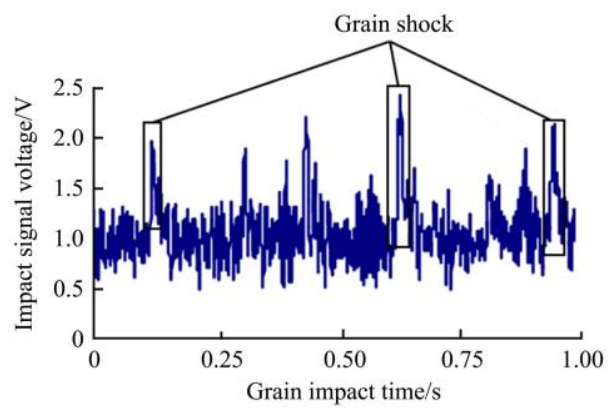

b. Feeding amount is $1.1 \mathrm{~kg} / \mathrm{s}$

Figure 15 Impact signal submerged in vibration signal

According to Equation (3), the average power of vibration interference signals in the four working conditions was calculated, and finally the vibration power in idle speed condition and high-speed standby was relatively small, which was about 1-3 mW. The vibration powers of the threshing idling and header idling were $157.365 \mathrm{~mW}$ and $92.427 \mathrm{~mW}$, respectively, which were about 2 to 3 times the power of the grain impact signal. According to Equation (4), the signal-to-noise ratio was calculated. The signal-to-noise ratio of threshing idling was $-9.29 \mathrm{~dB}$, and the signal-to-noise ratio of the header idling was $-4.67 \mathrm{~dB}$.

The fast Fourier transform was performed on the vibration interference signal of the grain flow sensor, and the frequency spectrum of the vibration interference was obtained.

It can be seen from the frequency spectrum of the vibration signal that the frequency of the vibration signal under different working conditions has significant differences, as shown in Figure 16. The frequencies of the vibration signal under idle speed conditions were $18 \mathrm{~Hz}, 40 \mathrm{~Hz}$ and $80 \mathrm{~Hz}$, etc., among which the vibration amplitude of $18 \mathrm{~Hz}$ was relatively small. The frequency of the vibration signal under high-speed standby was between $50 \mathrm{~Hz}$ and $125 \mathrm{~Hz}$, which was more than 5 times higher than that of the grain impact signal, and could be filtered by a filter. The main frequencies of the vibration signal under threshing idling were $23 \mathrm{~Hz}, 50 \mathrm{~Hz}, 80 \mathrm{~Hz}, 100 \mathrm{~Hz}$ and $125 \mathrm{~Hz}$. The strongest vibration signal frequency was $23 \mathrm{~Hz}$, which was close to the frequency of the grain impact signal, and it was difficult to filter through the filter. The frequency of the vibration signal under the idling of the header was $50 \mathrm{~Hz}$ and $70 \mathrm{~Hz}$, which could be filtered by a filter. It could be concluded from the spectrogram that the low-frequency vibration frequency of the combine harvester at idle speed was $18 \mathrm{~Hz}$, and the vibration signal was very weak. When the threshing drum and the header were working at the same time, there was a $23 \mathrm{~Hz}$ low-frequency strong vibration. The vibration frequency was close to the frequency of the grain impact signal, so it is difficult to eliminate it by spectral filtering.
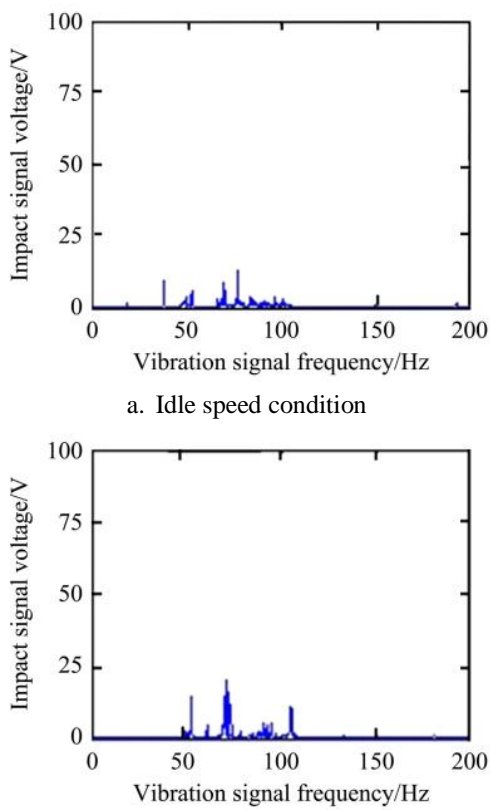

b. High-speed standby condition

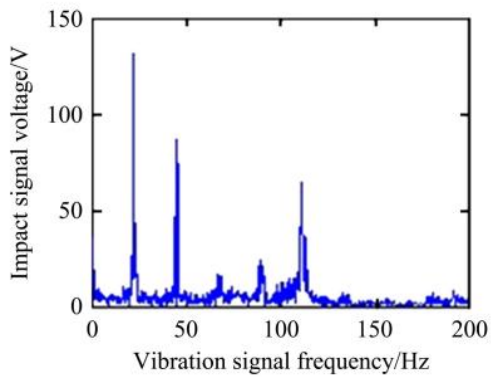

c. Threshing idling condition

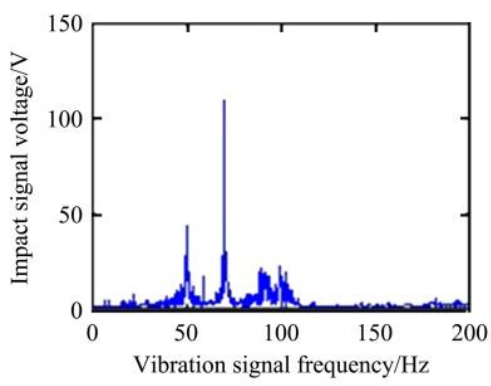

d. Header idling condition

Figure 16 Vibration spectrum of grain flow sensor under different working conditions

3.4 Eliminate the interference of combine harvester vibration on impact signal

3.4.1 Results of filtering to eliminate vibration interference

The filtered interference signal waveform is shown in Figure 17. Comparing the signals before and after filtering, it was found that low-pass filtering can filter the high-frequency components in the vibration signal and reduce the vibration interference to a certain extent, but the vibration spectrum of threshing idling and header idling had low-frequency components, and it could not be completely filtered. After filtering, the amplitude of the vibration interference signal of threshing idling was still $0.75 \mathrm{~V}$, and the vibration amplitude was still greater than the amplitude of the grain impact signal. 


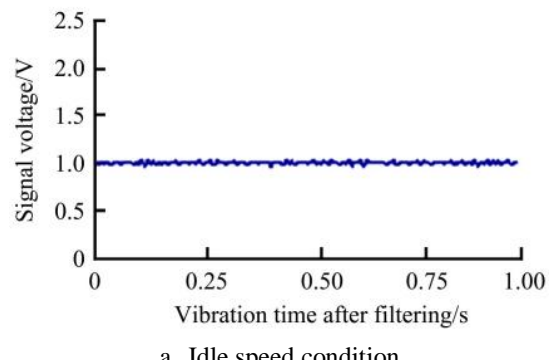

a. Idle speed condition

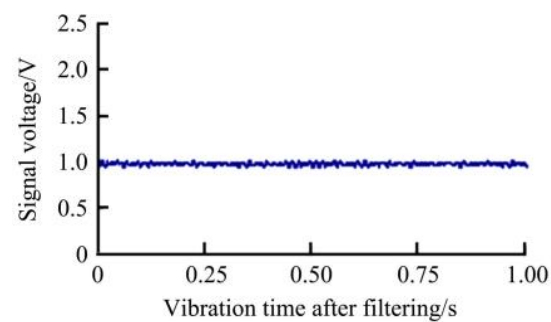

b. High-speed standby condition

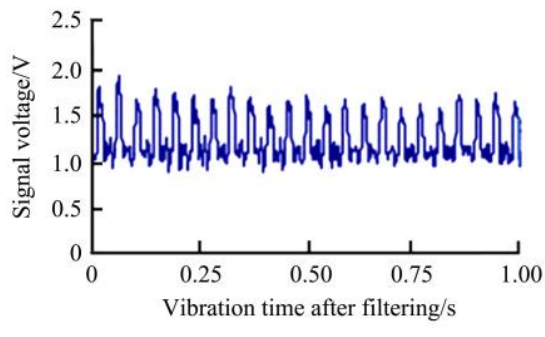

c. Threshing idling condition

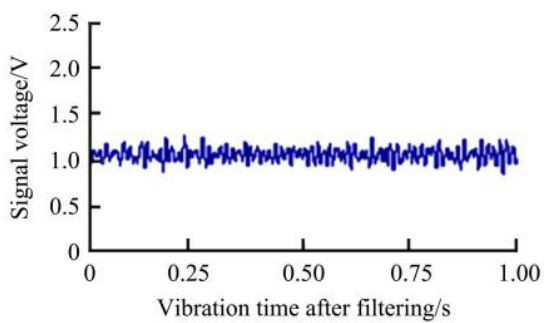

d. Header idling condition

Figure 17 Vibration signal after filtering

The vibration signal power was calculated before and after filtering in the four working conditions according to Equation (3), and the comparison result is shown in Figure 18. The vibration signal power of idle speed conditions and high-speed standby before filtering was small, and the vibration signal power after low-pass filtering was too small, which was not clearly shown in the figure. After filtering, the vibration signal power of threshing idling and header idling was significantly reduced.

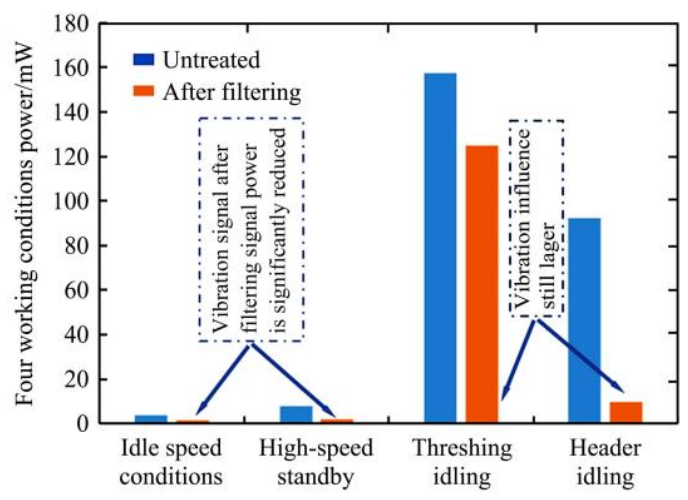

Figure 18 Vibration signal power before and after filtering

According to the impact test on the combine harvester platform, the impact signal power $P_{s}$ output by the grain flow sensor was
$54 \mathrm{~mW}$, when the grain flow rate was $2 \mathrm{~kg} / \mathrm{s}$. The vibration signal power was calculated according to the vibration signal of the combine harvester in the fourth working condition. The signal-to-noise ratio was $-4.67 \mathrm{~dB}$ before filtering, which meant that the vibration signal power at this time was bigger than the impact signal of the grain. The filtered signal-to-noise ratio was $15.41 \mathrm{~dB}$, which indicated that low-pass filtering could improve the sensor's signal-to-noise ratio. But it was difficult to filter low-frequency signals close to the grain impact frequency.

3.4.2 Results of adding a vibration isolation plate to eliminate vibration interference

The single-plate impact grain flow sensor after vibration isolation measures was installed on the combine harvester, and vibration tests were performed under four different working conditions. The data acquisition circuit using a low-pass filter to collect the vibration signal after vibration isolation is shown in Figure 19. Comparing the vibration signal amplitude before and after vibration isolation, it was found that the vibration isolation measures significantly reduce the vibration interference signal amplitude of the grain flow sensor, and the vibration amplitude from threshing idling and header idling was reduced from $0.75 \mathrm{~V}$ to $0.1 \mathrm{~V}$. The amplitude of the vibration interference signal was smaller than the amplitude of the grain impact signal (about $0.6 \mathrm{~V}$ ).

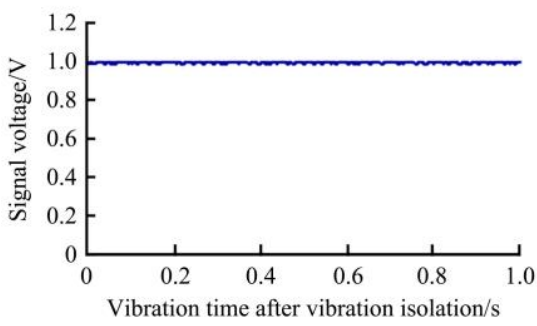

a. Idle speed condition
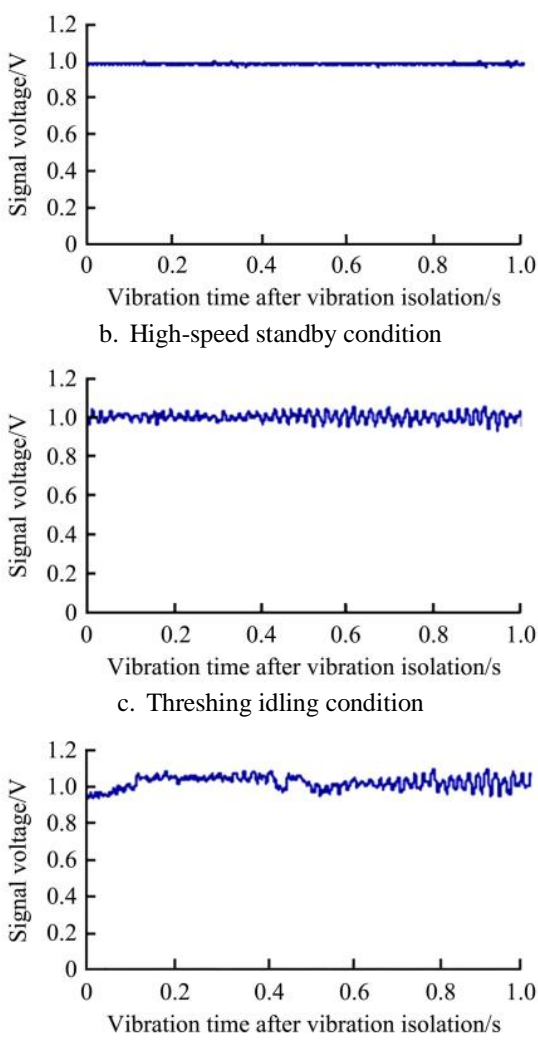

d. Header idling condition

Figure 19 Vibration signal after vibration isolation

According to Equation (3), the vibration signal power after vibration isolation under the four working conditions was 
calculated to be $0.039 \mathrm{~mW}, 0.071 \mathrm{~mW}, 0.483 \mathrm{~mW}$, and $1.869 \mathrm{~mW}$, respectively. Compared with the results before vibration isolation, the vibration interference power of the header idling at this time was the largest, as shown in Figure 20. The signal-to-noise ratio was calculated according to Equation (4), and the vibration isolation measures increased the signal-to-noise ratio of the sensor from $15.41 \mathrm{~dB}$ to $29.21 \mathrm{~dB}$. The comprehensive use of low-pass filtering and vibration isolation technology reduced the power of the vibration signal and improved the signal-to-noise ratio, but the vibration interference from the idling of the header would still have a greater impact on the grain impact signal.

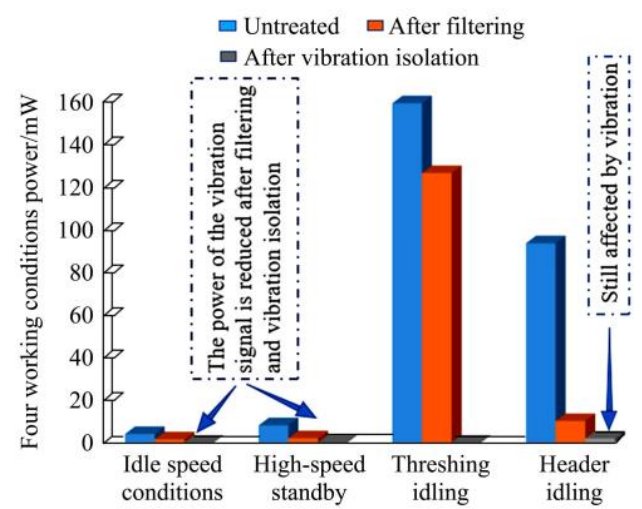

Figure 20 Vibration signal power before and after vibration isolation

The stress-strain analysis and impact characteristics of the single-plate impact grain flow sensor showed that the planar structure of the impact grain flow sensor was suitable for the grain flow test of the combine harvester, but the vibration test showed that vibration resistance of the single-plate impact grain flow sensor was poor.

3.4.3 Results of double-plate differential to eliminate vibration interference

The test platform was a combine harvester, which used a spiral grain elevator, and the maximum flow rate for normal harvest was $2 \mathrm{~kg} / \mathrm{s}$. The diversion bracket of the double-plate impact grain flow sensor was installed on the grain outlet of the combine harvester, and the impact plate and the vibration detection plate were installed vertically on the diversion bracket. The impact plate was facing the grain outlet and was $0.13 \mathrm{~m}$ away from the grain outlet. Referring to the previous vibration test, the combine was made in idle speed, engine high-speed idling, threshing drum high-speed and header idling. The feed volume of the header was 0 , so the signal voltage output by the impact plate and the vibration detection plate were all from the interference signal of the body vibration of the combine harvester. The data acquisition device was turned on, and the computer was used to collect the signals of the two channels under these four working conditions at the same time, and the data for $5 \mathrm{~min}$ in each working condition was collected. Simultaneously recorded the differential data of the two channels. When the combine harvester was threshing idling, which was the closest to the actual working condition, the rice was fed to the combine harvester at this time, and the computer collected the signals of the two channels when the grain impacted. The two-channel output signal and differential signal of the double-plate differential impact grain flow sensor after filtering under four working conditions are shown in Figure 21.

Through experiments under different working conditions, the intensity and frequency of the vibration signal of the combine harvester were changed, but the output voltage of the two channels was about $0.2 \mathrm{~V}$ after filtering, vibration isolation and difference. The feed amount of the grain flow sensor was 0 at this time, so it was considered that the zero point voltage of the differential output of the grain flow sensor was $0.2 \mathrm{~V}$. The power of the vibration signal before and after the difference of the four working conditions was calculated by Equations (5), (6), and (7), the results as shown in Table 2 .

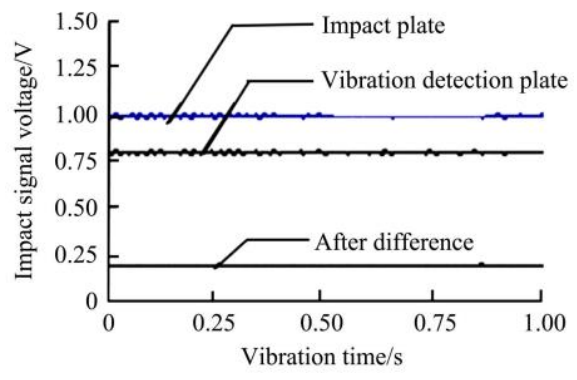

a. Idle speed condition

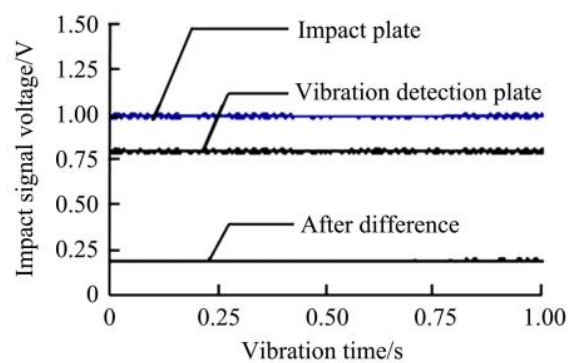

b. High-speed standby condition

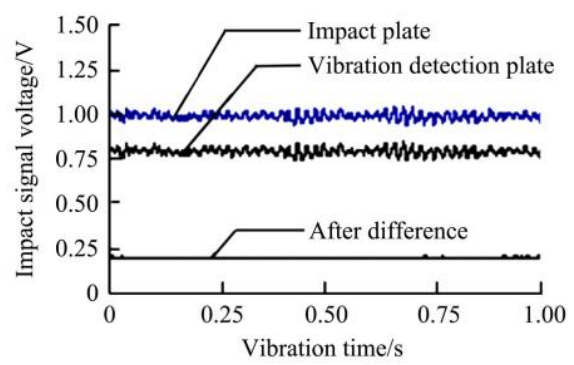

c. Threshing idling condition

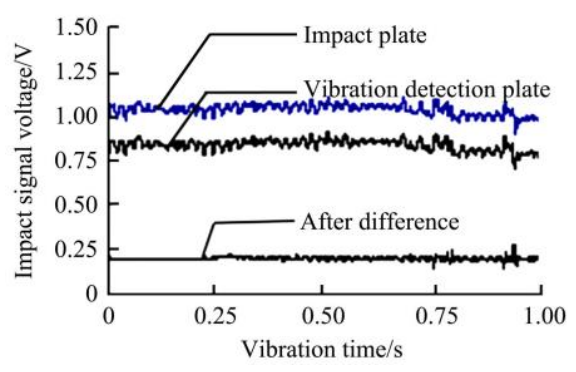

d. Header idling condition

Figure 21 Vibration signal and differential signal under different working conditions

Table 2 Vibration signal power before and after differential

\begin{tabular}{cccc}
\hline $\begin{array}{c}\text { Serial } \\
\text { number }\end{array}$ & $\begin{array}{c}\text { Working } \\
\text { condition }\end{array}$ & $\begin{array}{c}\text { Vibration signal power } \\
\text { before splitting /mW }\end{array}$ & $\begin{array}{c}\text { Vibration signal power } \\
\text { before splitting/mW }\end{array}$ \\
\hline 1 & Idle speed condition & 0.039328 & 0.004987 \\
2 & High-speed standby & 0.07056 & 0.003589 \\
3 & Threshing idling & 0.483134 & 0.002741 \\
4 & Header idling & 1.869124 & 0.062398 \\
\hline
\end{tabular}

It could be seen from Table 2 that the power of the vibration signal after the difference was much smaller than that before the difference.

When the feed rate of the combine harvester was $0.5 \mathrm{~kg} / \mathrm{s}$, the 
waveform output by the two channels of the sensor and the grain impact signal after the difference is shown in Figure 22. It could be seen from the figure that both the impact plate and the vibration detection plate would vibrate naturally after the grain impact, and the phase of the natural vibration signals of the two plates were not consistent, but the amplitude was small. After the difference, the self-amplitude of the sensor was about $0.02 \mathrm{~V}$, evenly distributed around the zero point voltage of $0.2 \mathrm{~V}$, and the influence of the positive and negative offset on the average value of the grain impact signal could be ignored. According to Equation (7), the differenced grain impact signal was calculated, and it was known that the average power of the grain impact signal at this time was about $20.8 \mathrm{~mW}$, and the signal-to-noise ratio was $50.45 \mathrm{~dB}$. When the grain flow reached the full range of $2 \mathrm{~kg} / \mathrm{s}$, the power of the grain impact signal was about $100 \mathrm{~mW}$, and the signal-to-noise ratio was $62.49 \mathrm{~dB}$.

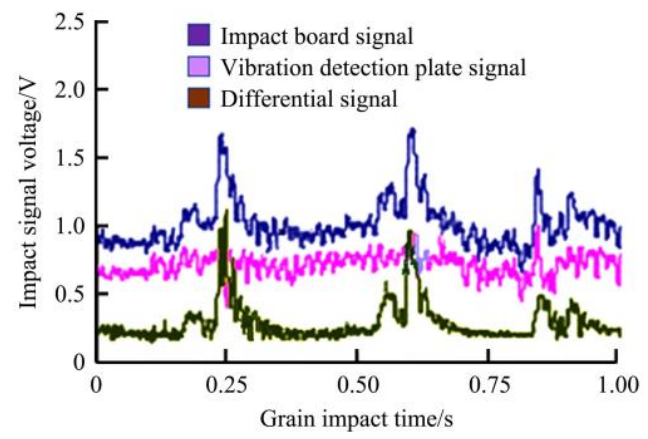

Figure 22 Grain shock signal

In summary, the double-plate differential impact grain flow sensor adopted the double-plate differential method to eliminate vibration interference signals from various working conditions of the combine harvester and improved the signal-to-noise ratio.

\subsection{Elimination of erroneous data results}

The data of the combine harvester in the field was collected, the real value was replaced by the arithmetic average of the regional yield, and the random error and gross error were eliminated respectively by the $3 \sigma$ criterion, and then the systematic error of the processed data was eliminated to obtain the real yield data. It took a certain time from the beginning of the harvesting work of the combine harvester to the movement of the grain in the harvester to the grain flow sensor. This period of time was called the filling time. During this time, the flow of grain gradually reached a stable value. From this point on, the yield value recorded by the yield monitoring system was the true yield value. Figure 23a, Figure 23b, Figure 23c respectively showed the wheat yield value, flow value and moisture content change curve with time within $47 \mathrm{~s}$ of the start of harvesting for five trains of combine harvesters. Among them, the series $A v$ represented the average wheat yield, flow rate, and moisture content change curve of five trains in $47 \mathrm{~s}$. (Wheat grains. The impact grain flow sensor obtains the grain mass through the impulse theorem, and the grain type has no influence on this article).

In the process of removing the filling time error, since the grain moisture content and grain flow had an impact on the calculation of grain yield, it was necessary to comprehensively consider the grain flow value, grain yield value and the grain moisture content value when they reached a stable level. Generally, a longer time was used as the filling time, and the data in this period of time could be filtered out as error data. In the figure, there were five trains of wheat data. The time to stabilize the yield was $32 \mathrm{~s}$, the time to stabilize the flow was $24 \mathrm{~s}$, and the average time to stabilize the moisture content was $20 \mathrm{~s}$, of which the longest time to stabilize was $32 \mathrm{~s}$, which meant that the filling time was $32 \mathrm{~s}$. Therefore, the data in the first $32 \mathrm{~s}$ of the recorded data were all filling time error data, which would be eliminated.

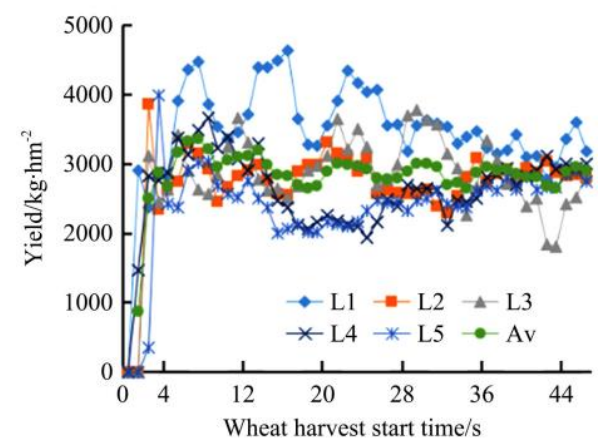

a. Change curve of wheat yield value at the beginning of harvest

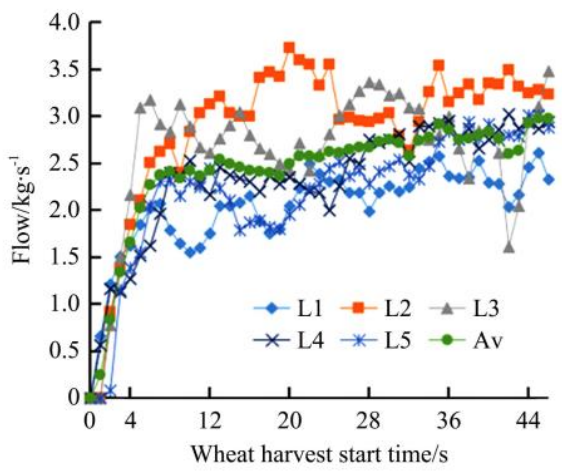

b. Change curve of the wheat flow value at the beginning of harvest

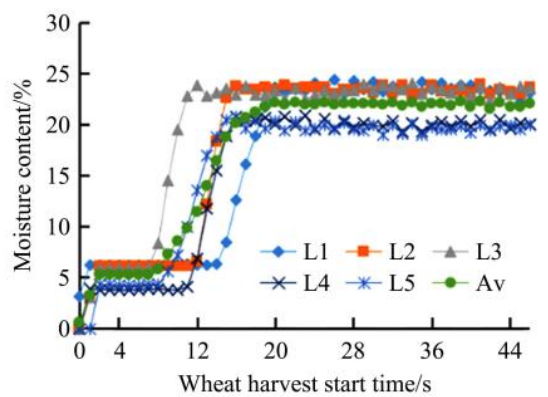

c. Change curve of wheat moisture content at the beginning of harvest

Figure 23 Change curve of wheat at the beginning of harvest

There was a period of time from when the combine harvester's header stops harvesting to when the surplus grain was emptied. This period of time was called the delay time. Therefore, the system should stop recording data from the moment when the grain flow started to drop, and the following data was the delay time error data. Figure 24a, Figure 24b, and Figure 24c respectively showed the change curve of wheat yield value, flow value and moisture content with time before harvesting of five trains of combine harvesters stop harvesting.

Since there was no phenomenon that the moisture content, flow rate and yield value drop to zero, some of the data information of these trains had been filtered out. Therefore, the water content of the L1 and L5 sets of data had a large change, while the water content of L2 and L3 remained basically stable, and the L4 data had a sudden change. It was concluded that the delay time error had been filtered out of the two sets of data of L2 and L3, and there was still a certain delay time error in the two sets of data of L1 and L5, which was about within the last $5 \mathrm{~s}$. The last singularity should be removed from the L4 data group, and the previous data should be interpolated to regenerate data. The data in the last $5 \mathrm{~s}$ of the recorded data were all delay time error data, and they were 
eliminated.

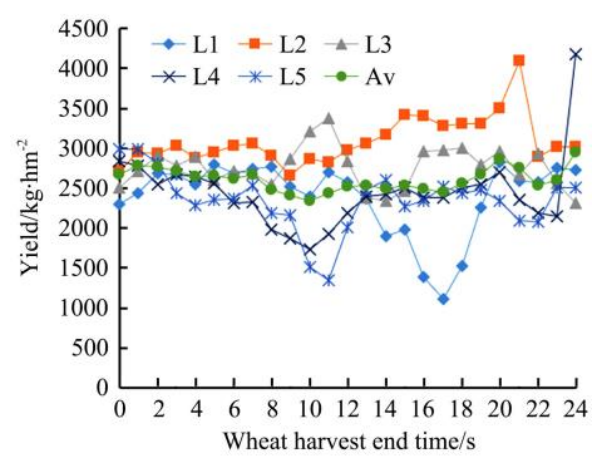

a. Change curve of wheat yield value before stopping harvesting

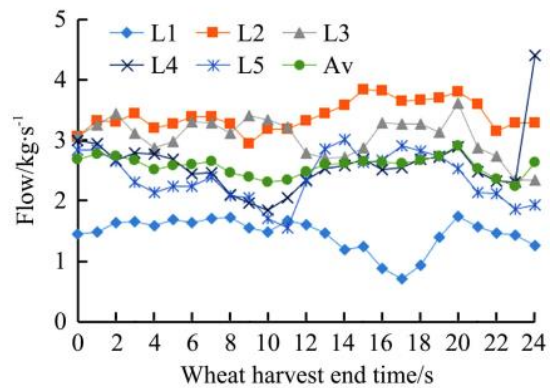

b. Change curve of the wheat flow value before the stop of harvesting

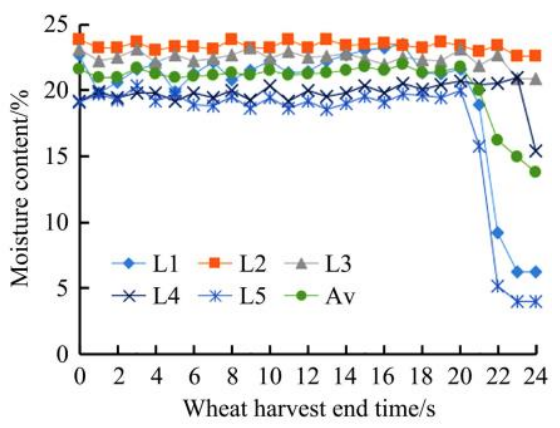

c. Change curve of wheat moisture content before stopping harvesting

Figure 24 Change curve of wheat when harvesting is stopped

\subsection{Results of the yield map}

In order to reduce the cost of precision agriculture practice and provide better modern agricultural equipment support, so as to realize the automatic collection of farmland information, it is necessary to improve equipment accuracy and process error data. The double-plate differential grain flow sensor was installed on the combine harvester to work in the field. The internal display of the harvester would show the yield situation through the yield data scatter plot, yield contour map and histogram. The double-plate differential grain flow sensor was installed on the combine harvester, and a wheat harvest experiment was carried out on the farm. During this harvesting process, an experimental area with a length of $200 \mathrm{~m}$, a width of $50 \mathrm{~m}$, and an area of $1 \mathrm{hm}^{2}$ was divided, and finally a set of wheat yield data was obtained. Through the analysis and processing of the data obtained in this experiment, the yield distribution map of the plot was drawn. After getting rid of the error data, the remaining data was drawn through MATLAB to draw the contour map of the yield data shown in Figure 25 and the scatter map of the yield data shown in Figure 26.

By analyzing Figure 25 and Figure 26, it could be found that the overall yield of this land was about $5000 \mathrm{~kg} / \mathrm{hm}^{2}$, and the yield value at the two ends of the ground was relatively small, which may be caused by people frequent walking or heavy soil compaction. Some low-yield spots were also found in the middle of the plot, which may be that the location was in the middle of the plot, and the application of fertilization, irrigation and pesticides did not meet the requirements. It could also be seen from the figure that the yield distribution in the middle of the plot was relatively even, while the yield changes at both ends of the plot were more dramatic.

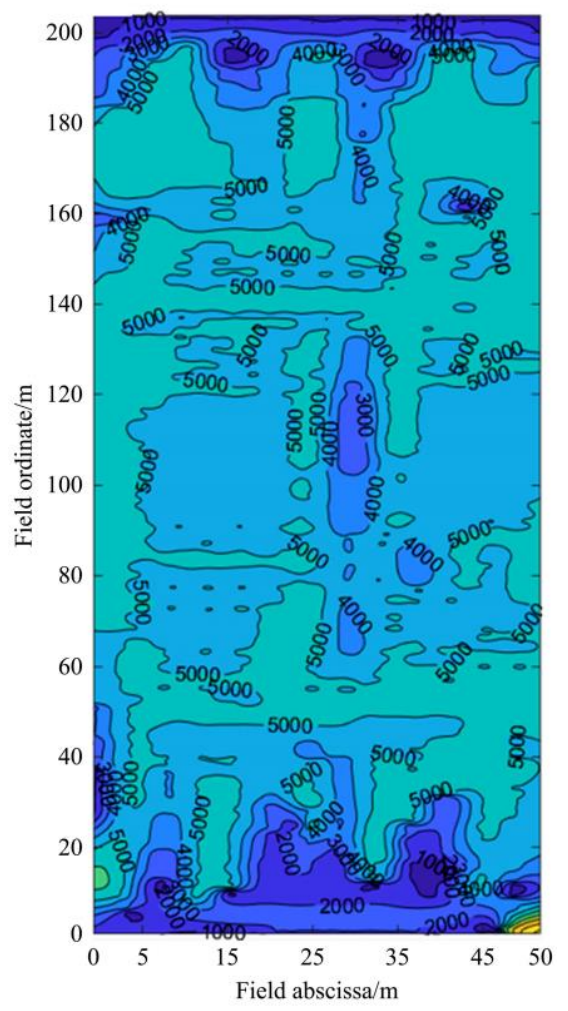

Note: Areas on each contour line indicate that their yield values are the same.

Figure 25 Contour map of production data

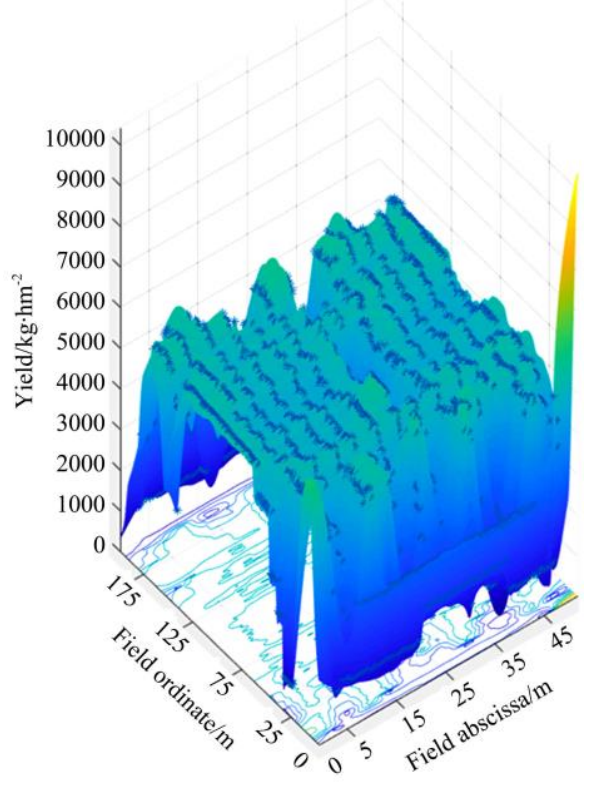

Figure 26 Scatter map of production data

Finally, the yield data histogram shown in Figure 27 was drawn by Excel. It could be seen intuitively from the figure that the number of yield in each yield interval and the proportion of each yield interval to the total yield. It could be seen that the proportion of the yield range below $4000 \mathrm{~kg} / \mathrm{hm}^{2}$ was relatively small, while the proportion of the yield range above $4000 \mathrm{~kg} / \mathrm{hm}^{2}$ was larger. Among them, the yield value of $1000 \mathrm{~kg} / \mathrm{hm}^{2}$ was too small, and there may be some soil problems and improper fertilization problems. The area should be found in combination 
with contour maps and scatter plots, and corresponding production plans should be made to increase grain yields.

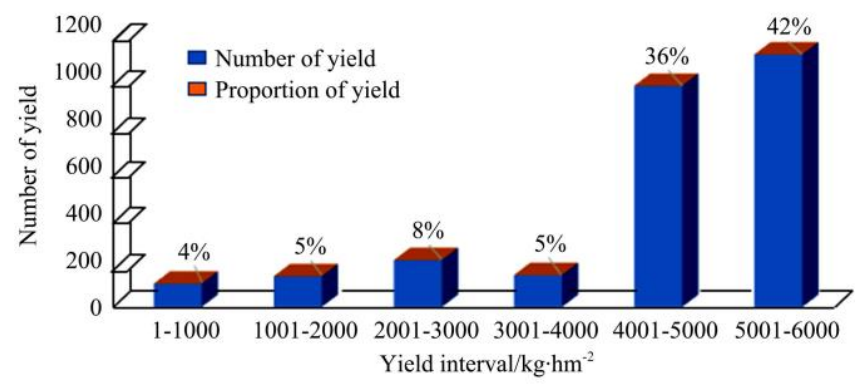

Figure 27 Histogram of production data

The parameters before and after the error filtering of the obtained output data were plotted as shown in Table 3.

Table 3 Comparison of parameters before and after error filtering of wheat yield data

\begin{tabular}{clcc}
\hline Serial number & \multicolumn{1}{c}{ Type of data } & Before filtering & After filtering \\
\hline 1 & Number of data & 2464 & 2440 \\
2 & Maximum $/ \mathrm{kg} \cdot \mathrm{hm}^{-2}$ & 5685 & 5685 \\
3 & Minimum $/ \mathrm{kg} \cdot \mathrm{hm}^{-2}$ & 372 & 825 \\
4 & Mean value $/ \mathrm{kg} \cdot \mathrm{hm}^{-2}$ & 4348.148 & 4386.969 \\
5 & Best value ratio & 15.16 & 6.89 \\
6 & Mean square error $/ \mathrm{kg} \cdot \mathrm{hm}^{-2}$ & 1317.33 & 1264.00 \\
7 & Coefficient of Variation & 0.3032 & 0.2882 \\
\hline
\end{tabular}

It could be seen from Table 3 that in this wheat harvest, and the combine harvester yield measurement system recorded a total of 2464 sets of yield data information. The error data was filtered by the filtering method of the value range $\left(750-7500 \mathrm{~kg} / \mathrm{hm}^{2}\right)$. A total of 24 sets of yield information were removed, accounting for $0.97 \%$ of the total original yield data. The clustering of the filtered yield data had been improved. The minimum yield had increased from $372 \mathrm{~kg} / \mathrm{hm}^{2}$ to $825 \mathrm{~kg} / \mathrm{hm}^{2}$, and the maximum ratio had been reduced from 15.16 to 6.89 , which made the data more reasonable. It could also be seen that the filtered yield data map had better smoothness, which reflected the yield distribution of this land to a certain extent. According to the analysis of the generated field yield distribution map, combined with other field information (such as soil fertility, soil moisture content, diseases and insect pests, etc.), the basis for subsequent variable operation management in the community could be obtained.

By installing the double-plate differential grain flow sensor on the combine harvester, compared with the previous impact grain flow sensor, the impact of vibration on the measurement results was reduced, the measurement accuracy was improved, and the measured data was more realistic and reliable. When working in the field, the yield data and location information collected by the combine harvester were used to accurately draw the yield distribution map of the field plot. Comparing and analyzing the obtained yield data scatter map, yield data contour map and yield data histogram, it could be seen that the yield value of each region was different. The causes of yield differences in combination with the land conditions in the field were analyzed, and the solutions were made in time to increase the value of field yields. It was also possible to make a reasonable charging plan based on the measured yield value to avoid conflicts caused by the operating costs of the harvester.

\section{Conclusions}

1) By filtering the single-plate impact grain flow sensor, the interference frequency above $50 \mathrm{~Hz}$ can be eliminated, but it is difficult to filter low-frequency signals similar to the grain impact frequency. After adding the vibration isolation plate, the amplitude of the vibration interference signal of the grain flow sensor is significantly reduced, but the vibration interference under the idling situation of the header will also have a greater impact on the grain impact signal. For this reason, a double-plate differential impact grain flow sensor is designed. After the signal was differenced, the self-amplitude of the sensor was about $0.02 \mathrm{~V}$, which was evenly distributed around the zero point voltage $0.2 \mathrm{~V}$, and the impact on the grain impact signal after the positive and negative offsets can be ignored.

2) The yield data obtained needs to undergo error processing, and the influence of random errors is reduced by using the arithmetic value as the true value of the measured yield. Then the gross errors data is filtered through the $3 \sigma$ criterion; Finally, it is verified through experiments that the data of the first $32 \mathrm{~s}$ of harvesting wheat belongs to the filling time error, while the data of the last $5 \mathrm{~s}$ of harvesting wheat belongs to the delay time error. The data after the error data is eliminated is true and effective.

3) 2464 sets of data were obtained through the harvest test, of which 24 sets of error data were eliminated, accounting for $0.97 \%$ of the original data. The yield data after eliminating error data were drawn into a scatter map of the yield data by MATLAB, and the size of the yield value in the region could be seen from the height of the points on the map. And through the yield data contour map, it is can be seen the area where the yield value of the field plot is equal. And through the yield data histogram drawn by Excel, the proportion of each yield interval in the whole area was obtained; The comprehensive analysis of the three yield distribution maps combining with the land conditions can help find the specific location of the low-yield area, and then analyze the reasons for the low yield in this area to make future planting plans, and increase the yield of the field.

\section{Acknowledgements}

This work was financially supported by the Open Project of the Key Laboratory of Modern Agricultural Equipment and Technology, Ministry of Education of the PRC (Grant No. JNZ201911), the Youth Talent Development and Program of Jiangsu University, and the Key Laboratory of Agricultural Equipment and Intelligent High Technology Research of Jiangsu Province.

\section{[References]}

[1] Rettore de Araujo Zanella A, da Silva E, Pessoa Albini L C. Security challenges to Smart Agriculture: Current state, key issues, and future directions. Array, 2020; 8: 100048. doi: 10.1016/j.array.2020.100048.

[2] Tzounis A, Katsoulas N, Bartzanas T, Kittas C. Internet of Things in agriculture, recent advances and future challenges. Biosystems Engineering, 2017; 164: 31-48. doi: 10.1016/j.biosystemseng.2017.09.007.

[3] Torky M, \& Hassanein A E. Integrating blockchain and the internet of things in precision agriculture: Analysis, opportunities, and challenges. Computers and Electronics in Agriculture, 2020; 178: 105476. doi: 10.1016/j.compag.2020.105476

[4] Kellengere Shankarnarayan V, Ramakrishna H. Paradigm change in Indian agricultural practices using Big Data: Challenges and opportunities from field to plate. Information Processing in Agriculture, 2020; 7(3): 355-368. doi: 10.1016/j.inpa.2020.01.001.

[5] Tang Y, Dananjayan S, Hou C J, Guo Q W, Luo S M, He Y. A survey on the $5 \mathrm{G}$ network and its impact on agriculture: Challenges and opportunities. Computers and Electronics in Agriculture, 2021; 180: 105895. doi: 10.1016/j.compag.2002.105895.

[6] Usman M, Farooq M, Wakeel A, Nawaz A, Alam S, ur Rehman H, et al. Nanotechnology in agriculture: Current status, challenges and future 
opportunities. Science of The Total Environment, 2020; 721: 137778. doi: 10.1016/j.scitotenv.2020.137778.

[7] González-García J, Swenson R L, Gómez-Espinosa A. Real-time kinematics applied at unmanned aerial vehicles positioning for orthophotography in precision agriculture. Computers and Electronics in Agriculture, 2020; 177: 105695. doi: 10.1016/j.compag.2020.105695.

[8] Munnaf M A, Haesaert G, Van Meirvenne M, Mouazen A M. Map-based site-specific seeding of consumption potato production using high-resolution soil and crop data fusion. Computers and Electronics in Agriculture, 2020; 178: 105752. doi: 10.1016/j.compag.2020.105752.

[9] Tang Z, Li Y, Li X, et al. Structural damage modes for rice stalks undergoing threshing. Biosystems Engineering, 2019; 186: 323-336

[10] Tang Z, Zhang B, Wang B, Wang M L, Chen H, Li Y M. Breaking paths of rice stalks during threshing. Biosystems Engineering, 2021; 204: 346-357.

[11] Yang Q, Shi L, Han J, Zha Y Y, Zhu P H. Deep convolutional neural networks for rice grain yield estimation at the ripening stage using UAV-based remotely sensed images. Field Crops Research, 2019; 235: $142-153$

[12] Fernandez-Gallego J A, Kefauver S C, Vatter T, Gutierrez N A, Nieto-Taladriz M T, Araus J L. Low-cost assessment of grain yield in durum wheat using RGB images. European Journal of Agronomy, 2019; 105: $146-156$

[13] Eugenio F C, Grohs M, Venancio L P, Schuh M, Bottega E L, Ruoso R, et al. Estimation of soybean yield from machine learning techniques and multispectral RPAS imagery. Remote Sensing Applications: Society and Environment, 2020; 20: 100397. doi: 10.1016/j.rsase.2020.100397.

[14] Chen J, Lian Y, Li Y. Real-time grain impurity sensing for rice combine harvesters using image processing and decision-tree algorithm. Computers and Electronics in Agriculture, 2020; 175: 105591. doi: 10.1016/j.compag.2020.105591.

[15] Jiang Z, Li A, Xu K J, Xiong W. Anti-strong pipeline vibration method combining frequency variance and amplitude feature for vortex flowmeter. Measurement, 2020; 166: 108193. doi: 10.1016/j.measurement.2020. 108193.

[16] Duan M L, Zong Y, Xu Y X, Chen GL, Lu W Q, Wei C, et al. Dual-channel interferometer for vibration-resistant optical measurement. Optics and Lasers in Engineering, 2020; 127: 105981. doi: 10.1016/ j.optlaseng.2019.105981.

[17] Lyu W L. Method for eliminating aerodynamic lift vibration of rigid rotor helicopters based on the novel sine-trim model. Aerospace Science and Technology, 2020; 98: 105655. doi: 10.1016/j.ast.2019.105655.

[18] Lee J C, Wang H Y, Schifano E D. Online updating method to correct for measurement error in big data streams. Computational Statistics \& Data Analysis, 2020; 149: 106976. doi: 10.1016/j.csda.2020.106976.

[19] Meyer B D, Mittag N. An empirical total survey error decomposition using data combination. Journal of Econometrics, 2021; 224(2): 286-305.

[20] Lu Y K, Liu W, Zhang Y, Li J Q, Luo W Q, Zhang Y Z, et al. An error analysis and optimization method for combined measurement with binocular vision. Chinese Journal of Aeronautics, 2020; 34(10): 282-292.

[21] Chubykalo A E, Espinoza A, Kosyakov B P. The origin of the energy-momentum conservation law. Annals of Physics, 2017; 384: 85-104.

[22] Liu R J, Zhang Z Q, Zhang M, Yang W, Li M Z. Performance analysis and modelling of impact-based sensor in yield monitor system. IFAC-PapersOnLine, 2018; 51(17): 613-618.

[23] Wang Y Z, Li G Q, Wang Y B, Lyu Y F. Simplified method to identify full von Mises stress-strain curve of structural metals. Journal of Constructional Steel Research, 2021; 181: 106624. doi: 10.1016/ j.jcsr.2021.106624.

[24] Tang Z, Zhang H T, Li H C, Li Y M, Ding Z, Chen J S. Developments of crawler steering gearbox for combine harvester straight forward and steering in situ. Int J Agric \& Biol Eng, 2020; 13(1): 120-126.
[25] Zeng G Q, Hu J A. The basic of engineering testing technique. Wuhan Huazhong University of Science and Technology, 2002; 297p.

[26] Pinto P M, Ferreira L H C, Colletta G D, Braga R A S. A 0.25-V fifth-order Butterworth low-pass filter based on fully differential difference transconductance amplifier architecture. Microelectronics Journal, 2019; 92: 104606. doi: 10.1016/j.mejo.2019.104606.

[27] Xu P F, Liu T Z, Pan S D, Zhou Z G. Numerical analysis for micro-vibration isolation of jointed sandwich plates with mass blocks. Materials Today Communications, 2018; 17: 341-354.

[28] Kwon S C, Jo M S, Ko D H, Oh H U. Viscoelastic multilayered blade-type passive vibration isolation system for a spaceborne cryogenic cooler. Cryogenics, 2020; 105: 102982. doi: 10.1016/j.cryogenics.2019. 102982.

[29] Su Y, Gao Z, Tu H, Wang Y R, Liu Y, Fang Z, et al. Uniformity and isotropy of speckle pattern cause the doubled random error phenomenon in digital image correlation. Optics and Lasers in Engineering, 2020; 131: 106097. doi: 10.1016/j.optlaseng.2020.106097.

[30] Lin N, Wang X P, Zhang Y H, Ji X P, Ruan J H. Fertigation management for sustainable precision agriculture based on Internet of Things. Journal of Cleaner Production, 2020; 277: 124119. doi: 10.1016/j.jclepro.2020. 124119

[31] Yang C H. Remote sensing and precision agriculture technologies for crop disease detection and management with a practical application example. Engineering, 2020; 6(5): 528-532.

[32] Méndez-Vázquez L, Lira-Noriega A, Lasa-Covarrubias $R$ Cerdeira-Estrada S. Delineation of site-specific management zones for pest control purposes: Exploring precision agriculture and species distribution modeling approaches. Computers and Electronics in Agriculture, 2019, 167: 105101. doi: 10.1016/j.compag.2019.105101

[33] van der Velde M, van Diepen C A, Baruth B. The European crop monitoring and yield forecasting system: Celebrating 25 years of JRC MARS Bulletins. Agricultural Systems, 2019; 168: 56-57.

[34] Franch B, Vermote E F, Skakun S, Roger J C, Becker-Reshef I, Murphy E et al. Remote sensing based yield monitoring: Application to winter wheat in United States and Ukraine. International Journal of Applied Earth Observation and Geoinformation, 2019; 76: 112-127.

[35] Lu C h, An X F, Ding H, Fu W Q, Li L W, Wu Q L, et al. Development of combine grain yield monitor system with self-feedback function. IFAC-PapersOnLine, 2018; 51(17): 408-411.

[36] Zheng Y P, Li G Y, Wang Z Y, Huang W, Kong Q D, Xi G Y, et al. Generation algorithm of grid model for complex terrain based on geodetic coordinate data transformation. Microprocessors and Microsystems, 2020 75: 103065. doi: 10.1016/j.micpro.2020.103065.

[37] Rao N M, Komal P, Maiti B, Das P K. Self-oscillatory loop flow of an external air-lift loop. Chemical Engineering Journal, 2020; 420(Part2): 127600. doi: 10.1016/j.cej.2020.127600.

[38] Ghadikolaei M A, Wei L, Cheung C S, Yung K F. Effects of engine load and biodiesel content on performance and regulated and unregulated emissions of a diesel engine using contour-plot map. Science of The Total Environment, 2019; 658: 1117-1130.

[39] Lee H S J, York C B. Compression and shear buckling performance of finite length plates with bending-twisting coupling. Composite Structures, 2020; 241: 112069. doi: 10.1016/j.compstruct.2020.112069.

[40] Nousi P, Tefas A, Pitas I. Dense convolutional feature histograms for robust visual object tracking. Image and Vision Computing, 2020; 99: 103933. doi: 10.1016/j.imavis.2002.103933.

[41] Hu J W. Design and research of double-plate differential impact grain flow sensor. Doctoral dissertation. Guangzhou: South China Agricultural University, 2009; 118p.

[42] Peng S P, Wu S S, Li Y Y, Chen H K. All-fiber monostatic pulsed laser Doppler vibr ometer: A digital signal processing method to eliminate cochannel interference. Optics \& Laser Technology, 2020; 124: 105952. doi: 10.1016/j.optlastec.2019.105952. 